\title{
Both young and older adults discount suggestions from older adults on a social memory test
}

\author{
Sara D. Davis • Michelle L. Meade
}

Published online: 9 February 2013

(C) Psychonomic Society, Inc. 2013

\begin{abstract}
In the present study, we examined the impacts of participant age and confederate age on social memory processes. During a collaborative recall phase, young and older adult participants were exposed to the erroneous memory reports of a young or an older adult confederate. On a subsequent individual recall test, young and older adult participants were equally likely to incorporate the confederates' erroneous suggestions into their memory reports, suggesting that participant age had a minimal effect on social memory processes. However, confederate age did have a marked effect: Young adult participants were less likely to incorporate misleading suggestions from older adult confederates and less likely to report "remembering" items suggested by older adult confederates. Critically, older adult participants were also less likely to incorporate misleading information from fellow older adult confederates. Both young and older adult participants discounted older adult confederates' contributions to a memory test.
\end{abstract}

\section{Keywords Social memory $\cdot$ Aging $\cdot$ False memory}

When we reminisce over shared experiences or impart unshared experiences with others, the goal of this reminiscence is typically to present an accurate view of the past. Unfortunately, memorial details are not always accurate, and when shared information is erroneous, memory errors may be transmitted from one individual to another. Memory distortions that arise from collaborative retellings have been well documented in younger adults (see Harris, Paterson, \& Kemp, 2008; Rajaram, 2011; Wright, Memon, Skagerberg, \& Gabbert, 2009, for reviews). However, much less is known about age differences in socially introduced misinformation. Are older adults more or less likely than young adults to

S. D. Davis $\cdot$ M. L. Meade $(\bowtie)$

Department of Psychology, Montana State University, Bozeman, MT 59717, USA

e-mail:mlmeade@montana.edu incorporate others' suggestions into their own memories? Does it matter if the erroneous details are suggested by a young or older adult?

To answer such questions, for the present study we manipulated both participant age and confederate age in the social contagion of memory paradigm (Meade \& Roediger, 2002; Roediger, Meade, \& Bergman, 2001). In this paradigm, individuals study visual scenes alongside a confederate. The participant and the confederate then take turns recalling items from each scene. Critically, the confederate suggests several items during this collaboration that had not been presented in the scenes. On subsequent individual recall and recognition tests, participants often incorporate the confederates' errors into their own memory reports, a process termed the social contagion of memory. Research in the related, memory conformity paradigm has also demonstrated the powerful effect of social influence on false memory (Allan \& Gabbert, 2008; Bodner, Musch, \& Azad, 2009; Gabbert, Memon, \& Allan, 2003; Gabbert, Memon, Allan, \& Wright, 2004; Gabbert, Memon, \& Wright, 2006, 2007; Garry, French, Kinzett, \& Mori, 2008; Mori \& Mori, 2008; Skagerberg \& Wright, 2008a, 2008b, 2009; Wright, Gabbert, Memon, \& London, 2008; Wright, Self, \& Justice, 2000).

One question addressed in the present study is whether susceptibility to socially introduced misinformation varies as a function of participant age. Older adults are generally more susceptible to memory errors than are young adults in individual false memory paradigms (Roediger \& McDaniel, 2007). However, research on age differences across social memory paradigms has yielded mixed evidence-namely that, relative to young adults, older adults in social falsememory paradigms are more susceptible (Meade \& Roediger, 2009), less susceptible (Gabbert et al., 2004; Ross, Spencer, Blatz, \& Restorick, 2008), or equally susceptible (Gabbert et al., 2003) to false memories.

Procedural differences across social memory paradigms may inform the predictions for the present study regarding the influence of participant age in the social contagion 
paradigm. Specifically, Meade and Roediger (2009) utilized a turn-taking procedure rather than the free-for-all discussion employed by Ross et al. (2008), and thus, spontaneous error correction by a collaborator was precluded (cf. Thorley \& Dewhurst, 2007). Furthermore, Meade and Roediger examined age differences in false memory following a prior collaboration, while Ross et al. examined age differences in false memory during collaboration. Given that in the present paradigm, the collaborative phase involved turn taking and the focus was on individual memory following prior collaboration, we predicted that older adults should demonstrate increased false memories relative to young adults (as in Meade \& Roediger, 2009).

In the present study, we also examined the role of confederate age on the social contagion effect. As was argued by Hirst and Echterhoff (2012), it is increasingly important to understand the influence of social-interpersonal moderators of social contagion effects. Confederate age may be an especially important social-interpersonal factor, because older adults are generally perceived as having less reliable memories than young adults (Levy, 1996), and recent research has demonstrated that participants' beliefs regarding the reliability of their partner's memory influences how likely participants are to incorporate confederate suggestions (Wright, London, \& Waechter, 2010). To our knowledge, Gabbert et al. (2004) is the only prior study to have employed an older adult confederate on a collaborative memory task. Using the memory conformity paradigm, they demonstrated that older adults were less susceptible to memory conformity than were young adults. However, young and older participants were paired only with age-matched peers. The present experiment is the first to compare young and older adults' memories across matched- and mixed-age dyads. Thus, we would be able to determine whether any effects of confederate age differ between young and older adult participants. Assuming that older adult confederates are viewed as being less credible on a memory test (Levy, 1996), young adult participants should demonstrate less social contagion when working with an older adult confederate than when working with a young adult confederate (cf. Kwong See, Hoffman, \& Wood, 2001; Wright et al., 2010). Furthermore, any reduction in social contagion from older adult confederates should be less for older adults than for young adults, given older adults' decreased source-monitoring abilities (Hashtroudi, Johnson, \& Chrosniak, 1989).

The present study extends previous research on age differences in social memory processes by examining both the age of the participant and the age of the confederate. Of interest would be whether older adults are more or less susceptible to socially suggested false memories than are young adults when the erroneous information is suggested by a young adult or by a fellow older adult confederate.

\section{Method}

Participants The participants were 36 Montana State University undergraduates (age range, 18-35 years, $M=$ $21.08)$ recruited from introductory psychology classes and 36 older adults (age range, $65-85$ years, $M=74.19$ ) recruited from the local community via newspaper advertisements. Young adults participated for course credit, while older adults received $\$ 10$ for participating. Consistent with findings that semantic memory typically increases with age (e.g., Park et al., 2002), older adults in the present study $(M=35.52)$ scored significantly higher than younger adults $(M=28.47)$ on the Shipley Vocabulary Scale, $t(70)=7.77, S E M=0.91$. Older adults were also more educated $(M=16.67$ years) than younger adults $(M=13.36$ years $), t(70)=7.06, S E M=$ 0.47 ; this was not surprising, given that the majority of young adults were freshmen in college. Older adults $(M=28.51)$ scored lower than did young adults $(M=29.50)$ on the MiniMental State Exam (MMSE), $t(70)=3.35, S E M=0.30$, although all participants tested within the clinically normal range. No age differences emerged on the memory anxiety questionnaire, $t<1.70$.

Design For the experiment, we utilized a $2 \times 2 \times 2 \times 2$ mixed design. Exposure to contagion items (contagion or control) and expectancy of the contagion items (high or low) were manipulated within participants. Confederate age (young or older adult) and participant age (young or older adult) were manipulated between participants. The primary dependent variables were false recall and false recognition of the suggested items.

Materials The materials included images of six household scenes developed by Roediger et al. (2001) to contain an average of 23.8 items. Two high- and two low-expectancy items relevant to each photo were designated as contagion items (items falsely suggested by the confederates as having been present in the scene). Expectancy was determined by pilot participants who generated items expected to be in hypothetical scenes; these items were intentionally excluded from the photographs so that they did not appear in the images (see Roediger et al., 2001). We predicted that young adults might be especially cautious in adopting lowexpectancy items from older adult confederates.

The 36-item source recognition test (from Meade \& Roediger, 2002) included 18 studied items, 12 contagion/control items, and six unrelated fillers.

A final series of questionnaires included the Shipley Vocabulary Scale (Shipley, 1940), the MMSE (Folstein, Folstein, \& McHugh, 1975), a demographics questionnaire, and a Memory Anxiety Scale (adapted from Davidson, Dixon, \& Hultsch, 1991, as in Huff, Meade, \& Hutchison, 2011). 
Procedure The procedure followed those of Roediger et al. (2001) and Meade and Roediger (2002). Briefly, one participant was tested with one confederate. Throughout the study, two young adults (mean age 21 years, range 20-22) and two older adults (mean age 75 years, range 73-77) served as confederates. The confederates were always male, and they followed a strictly defined script. The participant and confederate studied slides in preparation for a memory test. The slides were presented for $15 \mathrm{~s}$ each and were preceded by a title slide verbally read by the experimenter (e.g., "the toolbox scene"). After viewing all six slides, both participant and confederate were given a 4-min mathematical filler task.

Next, the participant and the confederate participated in a turn-taking collaborative recall phase in which they alternated, each recalling six items from each scene (for a combined total of 12 items/scene). During collaboration, the confederate recalled nonpresented contagion items in three of the six scenes (one low- and one high-expectancy item in Positions 4 and 6). Contagion scenes and order of expectancy were counterbalanced. For the remaining three scenes, only correct items were suggested, so the nonsuggested contagion items in these scenes served as control items.

The participant and confederate then completed individual written recall tests; they were placed in separate rooms to recall as many items as possible in 2 min for each scene. Furthermore, participants indicated whether they remembered or knew that each written item had been in the scene (Gardiner, 1988; Rajaram, 1993; Tulving, 1985). Remember responses indicated that participants recollected something specific about an item, while know responses indicated that participants recalled nothing specific about an item but were still certain that the item had been present.

Next, participants were given unlimited time to complete the source recognition test, which required them to indicate whether they remembered each item from the scene, the other participant, both or neither. Finally, the participants completed the final questionnaires and were debriefed.

\section{Results}

All results reported as statistically significant meet the criterion of $p<.05$.

False recall False-recall data are presented in Table 1. The final column represents the contagion effect, which is the difference in the proportions of contagion and control items recalled. A $2 \times 2 \times 2 \times 2$ mixed analysis of variance (ANOVA) revealed a significant social contagion effect, $F(1,68)=46.02, M S E=.05, \eta_{\mathrm{p}}{ }^{2}=.40$, and a main effect of expectancy, $F(1,68)=50.89, M S E=.05, \eta_{\mathrm{p}}^{2}=.43$.
Table 1 Mean proportions of false recall for high- and low-expectancy contagion and control items

\begin{tabular}{llll}
\hline & Contagion & Control & Contagion effect \\
\hline \multicolumn{2}{l}{ Young adults } & & \\
\multicolumn{2}{l}{ Young confederate } & & \\
Overall & .36 & .12 & .24 \\
High & $.50(.24)$ & $.20(.23)$ & \\
Low & $.22(.36)$ & $.04(.11)$ & \\
Older confederate & & \\
Overall & .20 & .10 & \\
High & $.31(.27)$ & $.20(.17)$ & \\
Low & $.09(.19)$ & $.00(.00)$ & \\
Older adults & & \\
Young confederate & .10 \\
Overall & .34 & .08 \\
High & $.48(.35)$ & $.10(.20)$ \\
Low & $.20(.21)$ & $.06(.13)$ & \\
Older confederate & \\
Overall & .26 & .14 \\
High & $.32(.27)$ & $.18(.18)$ \\
Low & $.13(.23)$ & $.10(.17)$ & .12 \\
\hline
\end{tabular}

The averages between the high- and low-expectancy items represent the overall contagion and control scores. Standard deviations are indicated in parentheses

Consistent with previous research (Meade \& Roediger, 2002; Roediger et al., 2001), the social contagion effect was greater for high-expectancy than for low-expectancy items (mean difference $=.25$ vs. .12 , respectively; Item Type $\times$ Expectancy interaction, $F(1,68)=7.13, M S E=$ $\left..04, \eta_{\mathrm{p}}{ }^{2}=.09\right)$. Importantly, we found no main effect of participant age, $F<1$ : Older adults demonstrated levels of social contagion equivalent to those of young adults. Also noteworthy is the marginal main effect of confederate age, $F(1,68)=3.53, M S E=.07, p=.06, \eta_{\mathrm{p}}^{2}=.05$, along with the significant Confederate Age $\times$ Item Type interaction, $F(1,68)=9.52, M S E=.05, \eta_{\mathrm{p}}{ }^{2}=.12$. Post-hoc $t$ tests revealed that contagion items suggested by young adult confederates $(M=.35)$ were more likely to be incorporated into the subsequent memory reports of participants than were suggestions from older adult confederates $(M=.23)$, $t(70)=2.90, S E M=.05$. For control items, however, no difference in reporting emerged when participants were paired with young $(M=.10)$ or older $(M=.12)$ confederates, $t<1$. Therefore, while confederate age had no impact on the baseline measure of false memory (as indicated by the control items), participants of both ages were less likely to incorporate the erroneous contagion items suggested by older adult confederates.

Remember/know judgments Table 2 presents the mean proportions of remember and know responses for contagion 
Table 2 Mean proportions of remember and know responses given for falsely recalled contagion items only, as a function of participant age and confederate age

High expectancy Low expectancy

\begin{tabular}{lll}
\hline $\begin{array}{l}\text { Young adults } \\
\text { Young confederate }\end{array}$ & & \\
Remember & $.22(.28)$ & $.06(.17)$ \\
Know & $.26(.30)$ & $.19(.31)$ \\
Older confederate & & \\
Remember & $.06(.13)$ & $.02(.08)$ \\
Know & $.24(.28)$ & $.07(.18)$ \\
Older adults & & \\
Young confederate & & $.09(.19)$ \\
Remember & $.13(.20)$ & $.09(.15)$ \\
Know & $.37(.30)$ & $.07(.18)$ \\
Older confederate & & $.09(.19)$ \\
Remember & $.18(.22)$ & \\
Know & $.19(.26)$ & \\
\hline
\end{tabular}

Standard deviations are in parentheses

items. For the remember responses, a $2 \times 2 \times 2 \times 2$ mixed ANOVA revealed main effects of item type, $F(1,68)=$ $10.43, M S E=.02, \eta_{\mathrm{p}}{ }^{2}=.13$, and expectancy, $F(1,68)=$ $7.35, M S E=.03, \eta_{\mathrm{p}}{ }^{2}=.10$, as well as an interaction between item type and expectancy, $F(1,68)=4.49, M S E=.02, \eta_{\mathrm{p}}{ }^{2}=$ .06. Participants were more likely to report remember responses for high-expectancy contagion items $(M=.15)$ than for low-expectancy contagion items $(M=.06), t(71)=$ $2.85, S E M=.03$, but they were equally likely to report remember responses for high- and low-expectancy control items, $t<1.1, p>.05$. Most interestingly, the ANOVA revealed an interaction between expectancy, participant age, and confederate age, $F(1,68)=3.96, M S E=.03, p=$ $.051, \eta_{\mathrm{p}}{ }^{2}=.06$. Post-hoc $t$ tests revealed that older adult participants were equally likely to report remember responses for items suggested by young and older adult confederates; no effect of confederate age appeared for either high-expectancy or low-expectancy items, $t \mathrm{~s}<1.9$, $p$ s $>.05$. In contrast, young adult participants were less likely to report remembering items suggested by older adult confederates than items suggested by young adult confederates. Specifically, for high-expectancy items, young adults were almost four times less likely to report remember responses for items suggested by older adult confederates $(M=.04)$ than to report such responses for the same items suggested by young adult confederates $(M=.14), t(34)=$ $2.48, S E M=.05$. Young adults did not differ in the proportions of remember responses awarded to low-expectancy items as a function of confederate age, $t=1.12, p>.05$.

A separate ANOVA conducted on know responses revealed only that participants reported more such responses for contagion items $(M=.19)$ than for control items $(M=$ $.03), F(1,68)=27.46, M S E=.04, \eta_{\mathrm{p}}{ }^{2}=.29$, and for highexpectancy $(M=.19)$ than for low-expectancy $(M=.07)$ items, $F(1,68)=31.02, M S E=.03, \eta_{\mathrm{p}}{ }^{2}=.31$. No other main effects or interactions were significant, $F_{\mathrm{s}}<3.26, p \mathrm{~s}>.05$.

Veridical recall A $2 \times 2$ between-participants ANOVA was conducted to determine the effects of confederate age and participant age on veridical recall (contagion and expectancy manipulations were not included, as these applied only to false recall). The ANOVA revealed only that older adult participants $(M=.20)$ demonstrated poorer overall recall than did young adult participants $(M=.33), F(1,68)=72.61, M S E=$ $.004, \eta_{\mathrm{p}}{ }^{2}=.52$, a finding consistent with established age differences in recall (Balota, Dolan, \& Duchek, 2000).

Source recognition Recognition data are displayed in Table 3. False recognition was defined as the proportion of contagion items that participants attributed to the scene ("Slide Only" plus "Both Slide and Confederate"). A 2 (item type $) \times 2$ (participant age) $\times 2$ (confederate age) betweenparticipants ANOVA performed on false recognition revealed only that the social contagion effect persisted on final recognition, $F(1,68)=8.20, M S E=.05, \eta_{\mathrm{p}}{ }^{2}=.12$. The magnitude of the effect was not influenced by participant age or confederate age, $F \mathrm{~s}<1.60, p \mathrm{~s}>.05$, most likely because the test directed young and older adults' attention to source information that could be utilized to reduce memory errors (cf. Multhaup, 1995).

Separate analyses computed on correct recognition revealed no main effects or interactions, all $F_{\mathrm{S}}<2.74$, indicating that young and older adults were matched on source recognition, a finding consistent with much research demonstrating few or no age differences on veridical recognition tests (e.g., Balota, et al., 2000; Craik \& McDowd, 1987).

\section{General discussion}

The present experiment revealed important findings regarding the role of age on social memory processes. First, young and older adults were equally likely to incorporate others' misleading suggestions into their own memory reports. This finding, though contrary to our prediction, is not unprecedented, given the equivocal nature of age-related changes in social false-memory paradigms (e.g., Gabbert et al., 2003; Henkel \& Rajaram, 2011; Meade \& Roediger, 2009; Ross et al., 2008) and in the related misinformation paradigm (see Roediger \& Geraci, 2007, for a review).

Most interesting is the finding that both young and older adults were less likely to incorporate suggestions from older adult confederates into their individual recall, and to the same degrees. Given that beliefs about a partner's memory 
Table 3 Mean proportions of veridical and false recognition for contagion and control items

\begin{tabular}{|c|c|c|c|c|}
\hline & \multicolumn{2}{|c|}{ Young adults } & \multicolumn{2}{|c|}{ Older adults } \\
\hline & $\mathrm{YC}$ & $\mathrm{OC}$ & $\mathrm{YC}$ & $\mathrm{OC}$ \\
\hline \multicolumn{5}{|l|}{ Contagion items } \\
\hline Slide only & $.19(.21)$ & $.21(.24)$ & $.40(.34)$ & $.48(.31)$ \\
\hline Both slide and confederate & $.31(.31)$ & $.20(.30)$ & $.12(.22)$ & $.11(.20)$ \\
\hline Total false recognition & $.51(.37)$ & $.42(.38)$ & $.52(.33)$ & $.59(.34)$ \\
\hline Confederate only & $.35(.29)$ & $.38(.34)$ & $.37(.34)$ & $.22(.29)$ \\
\hline Neither slide nor confederate & $.14(.18)$ & $.20(.19)$ & $.11(.14)$ & $.19(.27)$ \\
\hline \multicolumn{5}{|l|}{ Control items } \\
\hline Slide only & $.33(.27)$ & $.32(.27)$ & $.35(.31)$ & $.45(.34)$ \\
\hline Both slide and confederate & $.04(.07)$ & $.03(.07)$ & $.05(.10)$ & $.03(.09)$ \\
\hline Total false recognition & $.37(.27)$ & $.35(.24)$ & $.40(.32)$ & $.47(.34)$ \\
\hline Confederate only & $.05(.08)$ & $.06(.10)$ & $.04(.09)$ & $.06(.13)$ \\
\hline Neither slide nor confederate & $.58(.28)$ & $.59(.27)$ & $.56(.30)$ & $.45(.35)$ \\
\hline
\end{tabular}

YC denotes young confederates, and OC denotes older confederates. Standard deviations are in parentheses

influence the likelihood of incorporating confederate suggestions (Wright et al., 2010), and the negative stereotype regarding age and memory (Levy, 1996), young adults were expected to discount suggestions by older adult confederates. However, the finding that older adults were also less likely to incorporate their fellow older adults' suggestions is noteworthy.

Interestingly, the phenomenology of the confederate age effect varied. Young adults reported fewer remember responses for items suggested by older adult confederates, possibly because they deemed older adult confederates as being less credible sources of memory information, and discounted the confederates' reports accordingly (cf. Kwong See et al., 2001). In contrast, older adult participants' remember responses did not vary as a function of confederate age, a finding consistent with established age differences in metacognitive judgments (e.g., Jacoby, Bishara, Hessels, \& Toth, 2005).

Source-monitoring theory (Johnson, Hashtroudi, \& Lindsay, 1993) suggests that confederate age may influence the characteristics associated with an item at encoding, as well as the decision criterion used at retrieval, and thus may explain why the magnitude of social contagion was reduced with older adult confederates. Specifically, the presumed decline in older adults' memory ability and/or the salience of completing a memory task with an older adult may have increased the contextual details encoded during collaboration with older confederates, and so have made source confusions less likely. In addition, participants may use a more stringent decision criterion to incorporate items suggested by older adult confederates. Previous studies have demonstrated that participants' criteria for incorporating confederate suggestions can change with explicit warnings regarding confederate credibility (e.g., Meade \& Roediger, 2002). Importantly, in the present study, participants were not explicitly told anything about the confederates' credibility; any change in criterion resulted from the participants' inferred beliefs about older adults' memory suggestions (cf. Levy 1996; Wright et al., 2010). On the final source-monitoring recognition test, confederate age did not influence false recognition, probably because the test directed participants' attention to the source of misleading information, and thus minimized errors suggested by all confederates (cf. Multhaup, 1995).

In conclusion, the present study was the first in which both participant and confederate age on a social memory task have been examined. Young and older adult participants were equally susceptible to other peoples' misleading suggestions. However, the age of one's collaborator influenced the magnitude of the effect: Both young and older adult participants were less likely to immediately incorporate suggestions from older adult confederates than from young adult confederates.

Author note This research was completed in partial fulfillment of the Master of Science degree by the first author. Special thanks to Chase Ladd and Vladimir Perga for running participants and for serving as young-adult confederates; to Giles Cokelet and Jim Sargent for serving as older-adult confederates; and to Bethany Spring and Meghan Huntoon for running participants. We also thank Dan Gigone, Keith Hutchison, and Roddy Roediger for helpful discussions.

\section{References}

Allan, K., \& Gabbert, F. (2008). I still think it was a banana: Memorable "lies" and forgettable "truths". Acta Psychologica, 127, 299-308. doi:10.1016/j.actpsy.2007.06.001

Balota, D. A., Dolan, P. O., \& Duchek, J. M. (2000). Memory in healthy older adults. In F. I. M. Craik \& E. Tulving (Eds.), The 
Oxford handbook of memory (pp. 411-425). New York, NY: Oxford University Press.

Bodner, G. E., Musch, E., \& Azad, T. (2009). Reevaluating the potency of the memory conformity effect. Memory \& Cognition, 37, 1069-1076. doi:10.3758/MC.37.8.1069

Craik, F. I. M., \& McDowd, J. M. (1987). Age differences in recall and recognition. Journal of Experimental Psychology: Learning, Memory, and Cognition, 13, 474-479. doi:10.1037/0278-7393.13.3.474

Davidson, H. A., Dixon, R. A., \& Hultsch, D. F. (1991). Memory anxiety and memory performance in adulthood. Applied Cognitive Psychology, 5, 423-433. doi:10.1002/acp.2350050504

Folstein, M. F., Folstein, S. E., \& McHugh, P. R. (1975). Mini-mental state: A practical method for grading the cognitive state of patients for the clinician. Journal of Psychiatric Research, 12, 189-198. doi:10.1016/0022-3956(75)90026-6

Gabbert, F., Memon, A., \& Allan, K. (2003). Memory conformity: Can eyewitnesses influence each other's memories for an event? Applied Cognitive Psychology, 17, 533-543. doi:10.1002/acp.885

Gabbert, F., Memon, A., Allan, K., \& Wright, D. B. (2004). Say it to my face: Examining the effects of socially encountered misinformation. Legal and Criminological Psychology, 9, 215-227. doi:10.1348/ 1355325041719428

Gabbert, F., Memon, A., \& Wright, D. B. (2006). Memory conformity: Disentangling the steps towards influence during a discussion. Psychonomic Bulletin \& Review, 13, 480-485. doi:10.3758/ BF03193873

Gabbert, F., Memon, A., \& Wright, D. B. (2007). I saw it for longer than you: The relationship between perceived encoding duration and memory conformity. Acta Psychologica, 124, 319-331. doi:10.1016/j.actpsy.2006.03.009

Gardiner, J. M. (1988). Functional aspects of recollective experience. Memory \& Cognition, 16, 309-313. doi:10.3758/BF03197041

Garry, M., French, L., Kinzett, T., \& Mori, K. (2008). Eyewitness memory following discussion: Using the MORI technique with a Western sample. Applied Cognitive Psychology, 22, 431-439. doi:10.1002/acp. 1376

Harris, C. B., Paterson, H. M., \& Kemp, R. I. (2008). Collaborative recall and collective memory: What happens when we remember together? Memory, 16, 213-230.

Hashtroudi, S., Johnson, M. K., \& Chrosniak, L. D. (1989). Aging and source monitoring. Psychology and Aging, 4, 106-112. doi:10.1037/0882-7974.4.1.106

Henkel, L. A., \& Rajaram, S. (2011). Collaborative remembering in older adults: Age-invariant outcomes in the context of episodic recall deficits. Psychology and Aging, 26, 532-545. doi:10.1037/a0023106

Hirst, W., \& Echterhoff, G. (2012). Remembering in conversations: The social sharing and reshaping of memories. Annual Review of Psychology, 63, 55-79. doi:10.1146/annurev-psych-120710-100340

Huff, M. J., Meade, M. L., \& Hutchison, K. A. (2011). Age-related differences in guessing on free and forced recall tests. Memory, 19, 317-330.

Jacoby, L. L., Bishara, A. J., Hessels, S., \& Toth, J. P. (2005). Aging, subjective experience, and cognitive control: Dramatic false remembering by older adults. Journal of Experimental Psychology. General, 134, 131-148. doi:10.1037/0096-3445.134.2.131

Johnson, M. K., Hashtroudi, S., \& Lindsay, D. S. (1993). Source monitoring. Psychological Bulletin, 114, 3-28. doi:10.1037/ 0033-2909.114.1.3

Kwong See, S. T., Hoffman, H. G., \& Wood, T. L. (2001). Perceptions of an older female eyewitness: Is the older eyewitness believable? Psychology and Aging, 16, 346-350. doi:10.1037/0882-7974.16.2.346

Levy, B. (1996). Improving memory in old age through implicit selfstereotyping. Journal of Personality and Social Psychology, 71, 1092-1107.

Meade, M. L., \& Roediger, H. L., III. (2002). Explorations in the social contagion of memory. Memory \& Cognition, 30, 995-1009. doi:10.3758/BF03194318
Meade, M. L., \& Roediger, H. L., III. (2009). Age differences in collaborative memory: The role of retrieval manipulations. Memory \& Cognition, 37, 962-975. doi:10.3758/MC.37.7.962

Mori, K., \& Mori, H. (2008). Conformity among cowitnesses sharing same or different information about an event in experimental collaborative eyewitness testimony. Perceptual and Motor Skills, 106, 275-290. doi:10.2466/PMS.106.1.275-290

Multhaup, K. S. (1995). Aging, source, and decision criteria: When false fame errors do and do not occur. Psychology and Aging, 10, 492-497. doi:10.1037/0882-7974.10.3.492

Park, D.C., Lautenschlager, G., Hedden, T., Davidson, N.S., Smith, A.D., \& Smith, P.K. (2002). Models of visuospatial and verbal memory across the adult life span. Psychology and Aging, 7, 299-320

Rajaram, S. (1993). Remembering and knowing: Two means of access to the personal past. Memory \& Cognition, 21, 89-102. doi:10.3758/BF03211168

Rajaram, S. (2011). Collaboration both hurts and helps memory: A cognitive perspective. Current Directions in Psychological Science, 20, 76-81. doi:10.1177/0963721411403251

Roediger, H. L., III, \& Geraci, L. (2007). Aging and the misinformation effect: A neuropsychological analysis. Journal of Experimental Psychology: Learning, Memory, and Cognition, 33, 321-334. doi:10.1037/0278-7393.33.2.321

Roediger, H. L., III, \& McDaniel, M. A. (2007). Illusory recollections in older adults: Testing Mark Twain's conjecture. In M. Garry \& H. Hayne (Eds.), Do justice and let the sky fall: Elizabeth F. Loftus and her contributions to science, law, and academic freedom (pp. 105-136). Hillsdale, NJ: Erlbaum.

Roediger, H. L., III, Meade, M. L., \& Bergman, E. T. (2001). Social contagion of memory. Psychonomic Bulletin \& Review, 8, 365371. doi:10.3758/BF03196174

Ross, M., Spencer, S. J., Blatz, C. W., \& Restorick, E. (2008). Collaboration reduces the frequency of false memories in older and younger adults. Psychology and Aging, 23, 85-92. doi:10.1037/0882-7974.23.1.85

Shipley, W. C. (1940). A self-administering scale for measuring intellectual impairment and deterioration. Journal of Psychology: Interdisciplinary and Applied, 9, 371-377. doi:10.1080/ 00223980.1940 .9917704

Skagerberg, E. M., \& Wright, D. B. (2008a). The co-witness misinformation effect: Memory blends or memory compliance? Memory, 16, 436-442. doi:10.1080/09658210802019696

Skagerberg, E. M., \& Wright, D. B. (2008b). Manipulating power can affect memory conformity. Applied Cognitive Psychology, 22, 207-216. doi:10.1002/acp.1353

Skagerberg, E. M., \& Wright, D. B. (2009). Sibling differentials in power and memory conformity. Scandinavian Journal of Psychology, 50, 101-107. doi:10.1111/j.1467-9450.2008.00693.x

Thorley, C., \& Dewhurst, S. A. (2007). Collaborative false recall in the DRM procedure: Effects of group size and group pressure. European Journal of Cognitive Psychology, 19, 867-881. doi:10.1080/ 09541440600872068

Tulving, E. (1985). Memory and consciousness. Canadian Psychologist, 26, 1-12. doi:10.1037/h0080017

Wright, D. B., Gabbert, F., Memon, A., \& London, K. (2008). Changing the criterion for memory conformity in free recall and recognition. Memory, 16, 137-148. doi:10.1080/09658210701836174

Wright, D. B., London, K., \& Waechter, M. (2010). Social anxiety moderates memory conformity in adolescents. Applied Cognitive Psychology, 24, 1034-1045.

Wright, D. B., Memon, A., Skagerberg, E. M., \& Gabbert, F. (2009). When eyewitnesses talk. Current Directions in Psychological Science, 18, 174-178. doi:10.1111/j.1467-8721.2009.01631.x

Wright, D. B., Self, G., \& Justice, C. (2000). Memory conformity: Exploring misinformation effects when presented by another person. British Journal of Psychology, 91, 189-202. doi:10.1348/ 000712600161781 